\title{
QUALITY OF LIFE AND WORK LIMITATION AMONG SURVIVORS OF BREAST CANCER AT ZAGAZIG UNIVERSITY HOSPITALS, EGYPT
}

\author{
By \\ Hammam RAM ${ }^{1}$, El-Shafei DA ${ }^{1}$, Abdelsalam NM ${ }^{2}$ and Balata $\mathrm{SA}^{3}$ \\ ${ }^{1}$ Department of Community, Environmental and Occupational Medicine, ${ }^{2}$ Department of Public Health and \\ Preventive Medicine, ${ }^{3}$ Department of Clinical Oncology and Nuclear Medicine, \\ Faculty of Medicine, Zagazig University.
}

\begin{abstract}
Introduction: The number of breast cancer survivors is increasing worldwide in the labor market. The average age of Egyptian women who have breast cancer is significantly younger than the average age of American and European women. Survivors of breast cancer encounter stressful experience that affect their quality of life (QOL) and work productivity. Aim of work: To assess the quality of life (QOL) and work limitations among survivors of breast cancer and to determine the medical and socio-demographic predictors of both QOL and work limitations among the studied sample. Materials and Methods: A total of 134 survivors of breast cancer attending the Oncology and Nuclear Medicine outpatient clinics in Zagazig University Hospital were studied through the EORTC QLQ-C30 and EORTC QLQ -BR23 (the Arabic versions) and a questionnaire based upon the English version of the Work Limitations Questionnaire. Results: The studied participants mean age was $48.32 \pm 8.68$, and $68.66 \%$ of them work for more than forty hours per week. The studied females reported low mean scores of EROTC QLQ -C30 and BR-23 scales. The EROTC global QOL scores were significantly affected by: treatment type, years since cancer diagnosis, disease stage II and III, and working hours per week. The percentage of work productivity loss was $8.3 \%$ and it was significantly affected by: treatment type, years since cancer diagnosis, years since completing primary cancer treatment, and disease stage II and III. Conclusion: Working women with breast cancer in Egypt experience low scores of quality of life and need more attention and support programs to cope with their health status, treatment type, and work requirements.
\end{abstract}

Keywords: Breast cancer, Survivors, Quality of Life, Work productivity, EROTC QLQ -C30 and BR-23 scales. 


\section{Introduction}

Breast cancer is known to be the most common type of cancer among women. It has been estimated that nearly 1.7 million new cases of breast cancer have been diagnosed worldwide in 2012 representing about $12 \%$ of all new cancer cases and $25 \%$ of all cancer cases in women (Ferlay et al., 2017). In Egypt, the most common site of cancer in females is the breast, representing $38.8 \%$ of all cancers in women. A 3 -fold increase in incidence of cancer in 2050 relative to 2013 is what is expected next (Ibrahim et al., 2014).

Survival rates of breast cancer have increased in recent years due to early diagnosis and effective treatment (Murtezani et al., 2014). Cancer survivorship is defined as the time frame from cancer diagnosis through the balance of life (Ristovski-Slijepcevic , 2008). Patients diagnosed and living with breast cancer have a very stressful experience that has a serious impact on their quality of life (QOL) and work productivity (Nitkin et al., 2011).

QOL issues related to breast cancer have been extensively studied. Patients with breast cancer may experience different survival stages during their lives (e.g., acute survival, extended survival, and long-term survival), and the specific needs of patients at different stages may be different. So, patients' QOL should be assessed periodically across stages. Also, detailed information on the contributions of each domain should be assessed to estimate patients' overall QOL (Lu et al., 2009).

With increasing survivorship rates, many survivors of breast cancer need to return to work to regain a regular life style. Work is a fundamental component of psychosocial wellbeing, for cancer survivors, so addressing work-related needs among those patients is of great importance (Lundh et al., 2013 and Cheng et al., 2015). But some studies have demonstrated that breast cancer survivors experience persistent physical, emotional and motor issues which will have a significant impact on their work productivity and many studies have indicated that functional and work limitations can last up to several years after cancer diagnosis (Zenget al., 2016). The evaluation of work limitations, lower levels of work productivity, overall QOL and 
identification of factors affecting them in breast cancer survivors can provide invaluable information for understanding the patients' specific needs and developing strategies/ interventions to improve QOL and work productivity among those patients (Zenget al., 2016). Despite the considerable number of conducted studies regarding the impact of breast cancer QOL and work productivity, to date, this issue has been largely unstudied in Egypt.

\section{Aim of work}

To assess the quality of life (QOL) and work limitations among survivors of breast cancer and to determine the medical and socio-demographic predictors of both QOL and work limitations among the studied sample.

\section{Materials and Methods}

\section{- Study design:}

A cross-sectional study was conducted at clinical oncology outpatient clinics affiliated to Zagazig University' hospitals from April 1st 2017 to September 30th 2017. The selecting criteria were: Egyptian working females between the ages of
18-60, with a history of primary breast cancer and they completed the primary cancer treatment at least two years prior to the time of collecting the data of the present study.

\section{- Study sample:}

A sample of 181 survivors of breast cancer was selected by systematic random sampling technique from total number of 600 patients who attend the oncology outpatient clinic during the study period. The sample size was estimated by using Epi-info software version 6.1. The non-response rate was $20 \%$. So, the data from 134 female survivors of cancer were used in the current study.

\section{- Study methods}

Semi structured face to face interviews were conducted for about 30 minutes by the investigators with each participant at the outpatient clinic. During the interview, the following questionnaires were completed by each participant:

\section{General information questionnaire:}

That includes socio demographic characteristics, occupational data, and medical history (e.g. age, marital status, 
occupation, job status, working years, working hours per day, income, stage of disease, type of treatment, years since diagnosis and years since completing treatment).

\section{Quality of life assessment:}

The European Organization for Research and Treatment of Cancer (EORTC) questionnaires to assess the quality of life of patients with cancer was used. In the present study the researchers used, both EORTC QLQ-C30 (Version 3) and EORTC QLQ -BR23 Arabic versions (Fayers et al., 2001).

The EORTC QLQ-C30 incorporates nine multi-item scales: five functional scales (physical, role, cognitive, emotional, and social functioning), three symptom scales (fatigue, pain, and nausea/vomiting); and a Global Health Status/QOL scale. In addition to multiple single item scales that assess commonly reported symptoms by cancer patients such as (dyspnea, insomnia, appetite loss, constipation, diarrhea, and financial difficulties).

The EORTC QLQ-BR23, breast cancer module which focuses on systemic therapy side effects, arm and breast symptoms, body image, and includes several sexual functioning items.

According to EROTC guidelines the scale scores of both QLQ-C30 and BR23 questionnaires were calculated and transformed linearly. The range in score of all scales was from zero to one hundred. A high functional scale score signifies a high/healthy level of functioning while a high score for either symptom scale or item scale signifies a high level of symptomatology or problems.

\section{Loss of productivity measurement:}

The loss of productivity was measured through a questionnaire based upon the English language version of the Work Limitations Questionnaire (Lerner et al, 2001).

The questionnaire was used to measure the outcomes of work productivity loss in participants. It is a 25-item self-reporting measure of work limitations. In this measure, work limitation is inversely related to work productivity. The high scores of work limitations designate low productivity. 
A pilot study was conducted on 14 patients and a validity test for language clarity, content, relevancy, ease of understanding and time needed to answer was done on the questionnaire. A reliability test was done by using the reliability coefficients (Cronbach's alpha) which was high for all questionnaires, and suitable for scientific purposes. The results of the pilot study showed no difference from the main results so it was included in the main results.

\section{Consent}

Informed consent was obtained from every participant after assuring the privacy of their data and clarifying the aim of the study.

\section{Ethical approval}

The research protocol was approved by Zagazig University' Institutional Review Board and formal permission was obtained from the Chairman of Zagazig University Hospitals.

\section{Data management}

The SPSS program (Statistical Package for Social Science) version 15.0 was used to analyze the data where, qualitative data was represented as frequencies and percentages and quantitative data were represented as mean and standard deviation. Multiple regressions were used to identify the significant predictors affecting global QOL and work productivity loss. p-value $\leq 0.05$ was considered statistically significant and $\leq 0.01$ was considered highly significant. 


\section{Results}

Table (1): Socio-demographic and occupational characteristics of the studied survivors of cancer breast.

\begin{tabular}{|c|c|}
\hline Characteristics & $\begin{array}{l}\text { No }(\%) \\
(\text { No }=134)\end{array}$ \\
\hline $\begin{array}{l}\text { Age } \\
<40 \text { years } \\
40-50 \text { years } \\
50-60 \text { years }\end{array}$ & $\begin{array}{l}14(10.45) \\
68(50.75) \\
52(38.81) \\
48.32 \pm 8.68\end{array}$ \\
\hline $\begin{array}{l}\text { Marital status } \\
\text { Single } \\
\text { Married } \\
\text { Divorced } \\
\text { Widowed } \\
\end{array}$ & $\begin{array}{c}9(6.72) \\
100(74.63) \\
5(3.73) \\
20(14.93) \\
\end{array}$ \\
\hline $\begin{array}{l}\text { Highest education } \\
\text { Secondary and below } \\
\text { High school or above }\end{array}$ & $\begin{array}{l}90(67.16) \\
44(32.84)\end{array}$ \\
\hline $\begin{array}{l}\text { No. of children } \\
0-3 \\
\geq 3\end{array}$ & $\begin{array}{l}55(41.04) \\
79(58.96)\end{array}$ \\
\hline $\begin{array}{l}\text { Working hours /week } \\
\geq 40 \mathrm{~h} / \mathrm{w} \\
<40 \mathrm{~h} / \mathrm{w}\end{array}$ & $\begin{array}{l}92(68.66) \\
42(31.34)\end{array}$ \\
\hline $\begin{array}{l}\text { Occupation } \\
\text { Farmers/services } \\
\text { Clerical /sales /administrative }\end{array}$ & $\begin{array}{l}102(76.12) \\
32(23.88)\end{array}$ \\
\hline $\begin{array}{l}\text { Income } \\
\text { Enough } \\
\text { Not enough } \\
\end{array}$ & $\begin{array}{l}46(34.33) \\
88(65.67)\end{array}$ \\
\hline $\begin{array}{l}\text { Time since current job (years) } \\
<5 \text { years } \\
5-<10 \text { years } \\
\geq 10 \text { years }\end{array}$ & $\begin{array}{l}81(60.45) \\
42(31.34) \\
11(8.21) \\
4.78 \pm 2.93\end{array}$ \\
\hline Work productivity loss $\quad$ Mean \pm SD & $0.083 \pm 0.045$ \\
\hline
\end{tabular}

Table 1 showed that 134 female survivors of breast cancer were included in the current study, $50.75 \%$ were between the ages of 40 and $50,74.63 \%$ were married, with $\geq$ three children $(58.96 \%)$. As for occupational characteristics, most of them (76.12\%) were working as farmers/service staff for less than five years $(60.45 \%)$ and working for $\geq 40 \mathrm{~h}$ per week $(68.66 \%)$. As for the work limitation questionnaire productive loss scores (WLQPLS), the mean loss score was 0.083 , indicating the percentage of work productivity loss was $8.3 \%$. 
Table (2): Clinical characteristics of the studied sample.

\begin{tabular}{|l|c|}
\hline Clinical characteristics & $\begin{array}{c}\text { No (\%) } \\
(\mathbf{N o}=\mathbf{1 3 4})\end{array}$ \\
\hline Disease stage & $47(35.07)$ \\
Stage I & $68(50.75)$ \\
Stage II & $19(14.18)$ \\
Stage III & $10(7.46)$ \\
Type of treatment & $14(10.45)$ \\
Surgery only & $18(13.43)$ \\
Radiation only & $92(68.66)$ \\
Surgery + radiation $\quad$ Mean \pm SD & $4.19 \pm 2.13$ \\
Surgery + radiation+ chemotherapy & \\
\hline Years since cancer diagnosis & $3.28 \pm 1.02$ \\
\hline Years since completing primary cancer treatment \pm SD & \\
\hline
\end{tabular}

Table 2 showed that $50.75 \%$ of the participants were diagnosed at stage II of the disease, $68.66 \%$ were treated with a combination of surgery, radiation and chemotherapy. The mean of years since cancer diagnosis was $4.19(\mathrm{SD}=2.13)$. 
Table (3): Scores of EROTC QLQ -C30 and BR-23 scales of the studied sample.

\begin{tabular}{|c|c|}
\hline Scale & Mean (SD) \\
\hline $\begin{array}{l}\text { QLQ-C30 Global QOL and Functional Scales } \\
\text { Global QOL } \\
\text { Physical functioning } \\
\text { Role functioning } \\
\text { Emotional functioning } \\
\text { Cognitive functioning } \\
\text { Social functioning }\end{array}$ & $\begin{array}{l}51.98 \pm 25.73 \\
61.33 \pm 23.27 \\
59.89 \pm 28.56 \\
55.76 \pm 23.84 \\
62.54 \pm 16.57 \\
63.17 \pm 22.98\end{array}$ \\
\hline $\begin{array}{l}\text { QLQ-C30 Symptoms } \\
\text { Fatigue } \\
\text { Nausea / vomiting } \\
\text { Pain } \\
\text { Dyspnea } \\
\text { Insomnia } \\
\text { Appetite loss } \\
\text { Constipation } \\
\text { Diarrhea } \\
\text { Financial difficulties }\end{array}$ & $\begin{array}{c}31.45 \pm 16.32 \\
14.36 \pm 11.28 \\
25.89 \pm 20.23 \\
18.76 \pm 22.76 \\
31.09 \pm 27.34 \\
22.54 \pm 18.56 \\
16.79 \pm 21.61 \\
9.67 \pm 14.23 \\
28.56 \pm 17.98 \\
\end{array}$ \\
\hline $\begin{array}{l}\text { QLQ-BR23 Functional } \\
\text { Body image } \\
\text { Sexual functioning } \\
\text { Sexual enjoyment } \\
\text { Future perspective }\end{array}$ & $\begin{array}{l}69.67 \pm 30.45 \\
38.99 \pm 21.87 \\
44.76 \pm 29.08 \\
45.56 \pm 31.76\end{array}$ \\
\hline $\begin{array}{l}\text { QLQ-BR23 Symptoms } \\
\text { Systemic therapy side effects } \\
\text { Breast symptoms } \\
\text { Arm symptoms } \\
\text { Upset by hair loss }\end{array}$ & $\begin{array}{l}30.54 \pm 27.94 \\
27.64 \pm 18.78 \\
22.05 \pm 23.12 \\
50.89 \pm 30.56\end{array}$ \\
\hline
\end{tabular}

Table 3 showed that the total mean score of the global QOL for the participants was 51.98 \pm 25.73 . In the QLQ-C30, the highest functional score was found for 'social functioning' and the lowest symptom score was 'diarrhea'. While in the QLQ-BR23, the highest functional score was measured for 'body image' and the lowest symptom score was assessed for 'arm symptoms'. 
Table (4): Multiple linear regression analysis of significant predictors affecting global QOL and work productivity loss of the studied sample.

\begin{tabular}{|c|c|c|c|c|c|c|}
\hline \multirow[t]{2}{*}{ Independent variables } & \multicolumn{3}{|c|}{ EROTC global QOL } & \multicolumn{3}{|c|}{ Work productivity loss } \\
\hline & SEB & $\boldsymbol{\beta}$ & $\mathbf{t}$ & SEB & $\boldsymbol{\beta}$ & $\mathbf{t}$ \\
\hline $\operatorname{Age}(\geq 40$ years $)$ & 0.28 & $0.14^{*}$ & 1.83 & 0.09 & $0-.28$ & -12.52 \\
\hline Unmarried $^{\mathrm{a}}$ & 0.02 & $0.20 *$ & 2.11 & & & \\
\hline Secondary and below education & & & & 0.11 & 0.22 & 12.31 \\
\hline Working hours/week $(\geq 40 \mathrm{~h} / \mathrm{w})$ & 0.11 & $0.25 * *$ & 2.60 & 0.10 & $0.21 *$ & 11.53 \\
\hline Non enough income & 0.83 & $0.17 *$ & 12.23 & 0.35 & $0.16^{*}$ & 11.27 \\
\hline Disease stage (II\&III) & 0.32 & $0.38 * *$ & 19.43 & 0.09 & $0.22 * *$ & 13.47 \\
\hline $\begin{array}{l}\text { Surgery + radiation+ chemotherapy } \\
\text { treatment }\end{array}$ & 0.04 & $0.47 * *$ & 20.10 & 0.17 & $0.49 * *$ & 15.38 \\
\hline Years since cancer diagnosis & 0.51 & $0.46^{* *}$ & 7.63 & 0.68 & $0.46^{* *}$ & 14.94 \\
\hline $\begin{array}{l}\text { Years since completing primary cancer } \\
\text { treatment }\end{array}$ & 0.78 & $0.16^{* *}$ & 2.66 & 0.09 & $0.36 * *$ & 13.87 \\
\hline $\begin{array}{l}\mathbf{R}^{2}\left(\mathbf{a d j} \mathbf{R}^{2}\right) \\
\mathbf{F}(\mathbf{p})\end{array}$ & \multicolumn{3}{|c|}{$\begin{array}{c}0.43(0.42) \\
94.12(0.00)\end{array}$} & \multicolumn{3}{|c|}{$\begin{array}{l}0.66(0.63) \\
45.84(0.00)\end{array}$} \\
\hline
\end{tabular}

a Single, divorced, and widowed,

SEB :Standard Error of Beta,

$\beta$ :Standardized regression coefficient, t: t-statistic,

R2 : coefficient of determination,

Adj R2: Adjusted R square,

F: Analysis of variance F statistic,

* Significant

**Highly Significant

Table 4 showed that EROTC global QOL scores were significantly affected by treatment type $(\beta=0.47, p<0.01)$, years since cancer diagnosis $(\beta=0.46, p<0.01)$, disease stage II and III $(\beta=0.38, p<0.01)$, and working hours per week $(\beta=0.25$, $\mathrm{p}<0.01)$. As about work productivity loss, the most significant predictors were: treatment type $(\beta=0.49, p<0.01)$, years since cancer diagnosis $(\beta=0.46, p<0.01)$, years since completing primary cancer treatment $(\beta=0.36, \mathrm{p}<0.01)$, and disease stage II and III $(\beta=0.22, \mathrm{p}<0.01)$. 


\section{Discussion}

Both quality of life and work productivity are affected by the physical, psychological, functional and social complications encountered by the survivors of breast cancer. However, the number of researches in Egypt studying these aspects doesn't reflect either the magnitude or seriousness of these effects. The present study was conducted among a group of survivors of breast cancer working women to clarify the status of their quality of life and wok limitations. The percentage of female labor force in Egypt from total labor force was reported at $23.1 \%$ according to the data of the World Bank in 2016 (World Bank 2017). Moreover, the average age at presentation of breast cancer among Arab females is a decade earlier than in American and European females which coincides with their work productivity period and in consequence affects their work and represents a national economic burden. Also it was reported by earlier studies that younger onset cases usually associated with worse prognostic characteristics which in turn affects the quality of life of breast cancer survivors (Schlichtinget al., 2015). The median age of cancer breast diagnosis among Arab females is 48 years old (Najjar and Easson, 2010) this matches the results of the present study which showed mean age of the studied group at $48.32 \pm 8.68$ (Table 1).

For the functional domains of EROTC QLQ -C30 scales higher scores indicate a superior quality of life, while in the symptom domains higher scores represent a higher level of symptomatology. The results of the present study compared to the reference value manual of EROTIC OLO-30 showed worse global QOL $(51.98 \pm 25.73$ versus $61.8 \pm 24.6$ ), functioning scales; physical functioning $(61.33 \pm 23.27$ versus $78.4 \pm 21.3$ ), role functioning $(59.89 \pm 28.56$ versus $70.9 \pm 29.9)$, emotional functioning $(55.76 \pm 23.84$ versus $68.6 \pm 23.8), \quad$ cognitive functioning $\quad(62.54 \pm 16.57 \mathrm{vs} \quad 81.5 \pm$ $21.8)$, social functioning $(63.17 \pm 22.98$ versus $77.0 \pm 27.1$ ) and almost all of the symptoms scales except for fatigue and pain which were relatively close to the referenced EROTIC values (Table 1). Also, the present results showed worse scales than studies conducted in Europe and China (Schleife et al., 2014; Cheng 
et al., 2016; Harbeck et al., 2016 and Zeng et al., 2016). Scores of QOL30 among Arab women with breast cancer showed wide variation with the highest positive scores reported at UAE, Tunisia, Bahrain and Jordan. The lowest score was reported among Kuwaiti women with breast cancer. Discrepancy in QOL scores among Arab women can be related to different interpretations of QOL and selection bias (Rahou et al., 2016). In consistency with that, the low scores of QOL30 in the present study may be related to the characteristics of the selected sample derived from a governmental hospital which provides free treatment to the public and does not require any medical insurance so $76.12 \%$ of the female survivors of breast cancer participants are manual workers, work as farmers or in service jobs where high physical demands are required. Moreover, $68.66 \%$ of them work for more than 40 hours per week (Table 1). Also, $67.16 \%$ of female participants have secondary or lower education and $65.67 \%$ of them reported that they do not obtain a sufficient income (Table 1 ), which in consequence leads to a low socioeconomic status.
Regarding the EORTC BR-23 scores, the results of the present study revealed worse scores for body imaging $69.67 \pm 30.45$, future perspectives $45.56 \pm 31.76$, and the worst symptom was upset by hair loss that represents 50.89 \pm 30.56 (Table 3). Arab patients with breast cancer, 'Kuwaiti, Bahraini, and Jordanian women' also, showed results for the worst scores were for body image, future perspective, and upset by hair loss (Rahou et al., 2016). Also, the results of EORTC BR-23 scores among German female patients showed worst scores for body imaging $73.7 \pm 30.6$, sexual enjoyment $69.2 \pm$ 26.7, future perspectives $45.8 \pm 35.0$ and the worst symptom was also upset for hair loss $59.3 \pm 37.5$ (Waldmann et al., 2007).

Various factors are negatively associated with QOL and reduced work productivity among survivors of cancer. These factors are related to socio-demographics (e.g., old age, low education, low income), the disease condition (e.g., tumor site, tumor stage, types of treatment), and work related characteristics (e.g., job stress, physical work demands) (Zeng et al., 2016). 
The significant predictors of poor global quality of life among breast cancer survivors in the present study were treatment type, years since cancer diagnosis, disease stage II and III and working hours per week (Table 4). This was consistent with previous studies that have shown that time since diagnosis, disease stage, type of treatment are correlated with global quality of life ( Kessler, 2002; Bloom et al., 2004 and Zeng et al., 2016). While in some other researches done on patients during the first year after diagnosis it was found that medical variables (e.g., type of surgery, stage, and type of adjuvant therapy) were not predictors of QOL; rather, age and measures of current physical and emotional well-being were the most statistically significant predictors in various analyses .This is explained by change in predictors in global quality of life between short term and long term survivors (Ganz et al., 1990 and Shimozuma et al., 1999) .

The percentage of work productivity loss in the present study was $8.3 \%$ which is lower than Zeng et al., 2016 (16\%) who attributed their higher results to the calculation of both survivors of cervical cancer and breast cancer together, as cervical survivors in their study were mainly from a low social status.

In the present study, the significant predictors of reduced work productivity among the studied survivors of breast cancer were: treatment type, years since cancer diagnosis, and years since completing primary cancer treatment and disease stage II and III (Table 4). The possible effects of chemotherapy and radiotherapy stress are associated with the type of manual work and low socioeconomic status, which is the main characteristics of the studied sample, may explain the present results (Table 1 and 2). Further studies are needed to be conducted on a large sample to establish more proper associations.

\section{Conclusion}

The studied sample of survivors of breast cancer among Egyptian women showed low mean scores of all domains of EROTC QLQ-C30 and BR-23 scales. The significant predictors of poor global QOL among them were: treatment type, years since cancer diagnosis, disease stage II and III, and working hours per week. Moreover, their percentage of work productivity loss was $8.3 \%$ which 
was mainly affected by: treatment type, years since cancer diagnosis, years since completing primary cancer treatment, and disease stage II and III. So, implementing early detection programs for breast cancer among women in Egypt is recommended. Also, supportive programs to help them to cope with their health status, treatment type and work requirements are needed.

\section{Limitations of the study}

This study was conducted on a sample of females with breast cancer who received a free medical service in outpatient clinics at Zagazig University Hospitals. The studied sample was of low socio economic status and had jobs that were not supported by any medical or social insurance.

\section{Conflict of interests}

The authors declared that there is no conflict of interests.

\section{Funding}

\section{None}

\section{Acknowledgment}

The authors would like to thank all participants of the study for their cooperation.

\section{References}

1. Bloom JR, Stewart SL, Chang S and Banks PJ (2004): Then and now: quality of life of young survivors of breast cancer. Psycho-Oncology; 13(3):147-60.

2. Cheng AS, Zeng Y and Feuerstein M (2015): Validation of the Chinese version of the Cognitive Symptom Checklist-Work-21 in breast cancer survivors. Journal of Occupational Rehabilitation; 25(4):685-95.

3. Cheng AS, Lau LO, Ma YN, Ngai RH and Fong SS (2016): Impact of Cognitive and Psychological Symptoms on Work Productivity and Quality of Life among Survivors of breast cancer in Hong Kong. Hong Kong Journal of Occupational Therapy; 28:15-23.

4. Fayers PM, Aaronson NK, Bjordal K, Groenvold M, Curran D, et al. (2001): on behalf of the EORTC Quality of Life Group. The EORTC QLQ-C30 Scoring Manual (3rd Edition). Published by: European Organization for Research and Treatment of Cancer, Brussels.

5. Ferlay J, Soerjomataram I, Ervik M, Dikshit R, Eser S, et al. (2014): GLOBOCAN 2012 Vol 1.1, Cancer Incidence and Mortality Worldwide: IARC Cancer Base No. 11 [Internet]. Lyon, France: International Agency for Research on Cancer; Available at: http://globocan.iarc.fr, [accessed on 16 April 2017].

6. Ganz PA, Schagi CA and Cheng HL (1990): Assessing the quality of life-a study in newlydiagnosed patients of breast cancer. Journal of Clinical Epidemiology; 43(1):75-86.

7. Harbeck N, Iyer S, Turner N, Cristofanilli M, Ro J, et al. (2016): Quality of life with palbociclib plus fulvestrant in previously treated hormone receptor-positive, HER2-negative metastatic breast cancer: patient-reported outcomes from the PALOMA-3 trial. Annals of Oncology; 27(6):1047-54.

8. Ibrahim AS, Khaled HM, Mikhail NN, Hoda B and Hossam K (2014): Cancer incidence in Egypt: results of the national population-based 
cancer registry program. J Cancer Epidemiol; doi: 10.1155/2014/437971:1-18.

9. Kessler TA (2002): Contextual variables, emotional state, and current and expected quality of life in breast cancer survivors. Oncology nursing forum ; 29 (7).

10. Lerner D, Amick BC, Rogers WH, Malspeis S, Bungay K, et al (2001): The work limitations questionnaire. Medical care; 39(1):72-85.

11. Lu W, Cui Y, Chen X, Zheng Y, Gu K, et al (2009): Changes in quality of life among patients of breast cancer three years postdiagnosis. Breast Cancer Research and Treatment; 114(2):357.

12. Lundh $\mathrm{MH}$, Lampic $\mathrm{C}$, Nordin $\mathrm{K}$, Ahlgren J, Bergkvist L, et al (2013): Changes in healthrelated quality of life by occupational status among women diagnosed with breast cancer-a population-based cohort study. PsychoOncology; 22(10):2321-31 .

13. Murtezani A, Ibraimi Z, Bakalli A, Krasniqi S, Devolli Disha E, et al. (2014): The effect of aerobic exercise on quality of life among survivors of breast cancer: A randomized controlled trial. Journal of Cancer Therapeutics and Research; 10 (3): 658-664.

14. Najjar $\mathrm{H}$ and Easson $\mathrm{A}$ (2010): Age at diagnosis of breast cancer in Arab nations. International Journal of Surgery; 8(6):448-52.

15. Nitkin P, Parkinson M and Schultz IZ (2011): Cancer and work: a Canadian perspective. Canadian Association of Psychosocial Oncology. Jan. Available at https://www.capo. ca/pdf/CancerandWork-ACanadianPerspective. pdf [accessed 11 May 2017].

16. Rahou BH, El Rhazi K, Ouasmani F, Nejjari C, Bekkali R, et al. (2016): Quality of life in
Arab women with breast cancer: a review of the literature. Health and quality of life outcomes; 14(1):64.

17. Ristovski-Slijepcevic S (2008): Environmental scan of cancer survivorship in Canada: conceptualization, practice and research. Vancouver, BC: BC Cancer Agency.

18. Schleife H, Sachtleben C, Barboza CF, Singer S and Hinz A (2014): Anxiety, depression, and quality of life in German ambulatory patients of breast cancer. Breast cancer; 21(2):208-13.

19. Schlichting JA, Soliman AS, Schairer C, Harford JB, Hablas A, et al. (2015): Breast cancer by age at diagnosis in the Gharbiah, Egypt, population-based registry compared to the United States surveillance, epidemiology, and end results program, 2004-2008. BioMed Research International; 2015.

20. Shimozuma K, Ganz PA, Petersen L and Hirji K (1999): Quality of life in the first year after breast cancer surgery: rehabilitation needs and patterns of recovery. Breast Cancer Research and Treatment; 56(1):45-57.

21. Waldmann A, Pritzkuleit R, Raspe $\mathrm{H}$ and Katalinic A (2007): The OVIS study: health related quality of life measured by the EORTC QLQ-C30 and-BR23 in German female patients with breast cancer from Schleswig-Holstein. Quality of Life Research; 16(5):767-76.

22. World Bank. Labor force, female (\%of total labor force): 2017 available at: https://data. worldbank.org/indicator/SL.TLF.TOTL.FE.ZS [accessed, 15 November 2017].

23. Zeng Y, Cheng A, Liu X and Feuerstein M (2016): Symptom profiles, work productivity and quality of life among Chinese female cancer survivors. Gynecol Obstet (Sunnyvale); 6(357):2161-0932. 